\title{
BIODIVERSIDADE FLORESTAL E PAISAGÍSTICA DO TERRITÓRIO MUNICIPAL DE SELLANO - ÚMBRIA - ITÁLIA
}

\author{
Ettore Orsomando** \\ Federico Maria Tardella** \\ Marcello Martinelli***
}

\section{RESUMO:}

O Município de Sellano, situado na Úmbria (Itália), ocupando uma superfície de cerca $86 \mathrm{~km}^{2}$ no setor regional central mais oriental junto à fronteira com as Marcas, do ponto de vista florestal se destaca pelo elevado índice de cobertura florestal superior a $60 \%$ em relação aos $40 \%$ da Úmbria. A biodiversidade florestal é constituída por 7 formações de caducifólias naturais (florestas: de Quercus pubescens, de Ostrya carpinifolia, de Quercus cerris com a associação endêmica denominada Carici sylvaticae-Quercetum cerridis rica em Orquídeas, de Quercus cerris com Quercus pubescens, de Castanea sativa, de Fagus sylvatica, de Salix alba) e por um artificialismo (reflorestamentos de Pinus nigra e Pinus halepensis). Tais florestas, voltadas para a exploração econômica, em bom estado de conservação, contornadas por áreas de pastagem, por áreas antrópicas com ocupações humanas, áreas cultivadas e zonas de artesanato caracterizam 11 unidades ambientais paisagísticas do conjunto das 42 tipologias de paisagens da Região Úmbria como um todo: vertentes alto-colinares com florestas de Quercus pubescens ou de Ostrya carpinifolia, às vezes interrompidas por pequenas clareiras de pastagens, de origem secundária, de Bromus erectus; vertentes montanas com florestas de Fagus sylvatica e pequenas pastagens, de origem secundária, de Bromus erectus; áreas rupestres com agrupamentos casmofiticos; vertentes alto-colinares e submontanas, com fraca declividade e recobertas por paleossolos fersialíticos, com florestas mesófilas de Quercus cerris (Carpinion betuli) e florestas de Castanea sativa de origem antrópica; relevos alto-colinares com florestas de Ostrya carpinifolia ou Quercus pubescens, às vezes interrompidas por pequenas clareiras de pastagem, de origem secundária, de Brachypodium rupestre; leitos fluviais com florestas meso-higrófilas de Salix alba ou Alnus glutinosa; cimos e vertentes com pastagens de origem secundária de: Bromus erectus, Sesleria nitida e Cynosurus cristatus; implantações arbóreas (reflorestamentos por coníferas); áreas agrícolas dos relevos colinares com culturas anuais; aglomerados urbanos em área rural de encosta e de colina; áreas agrícolas das planícies aluvionares com culturas anuais.

O objetivo fundamental desse artigo, além de divulgar a biodiversidade florestal e paisagística que caracteriza o patrimônio naturalístico do Município de Sellano, foi o de contribuir, através do estudo geobotânico-paisagístico a definição da zona fito-microclimática circunscrita ao território municipal. PALAVRAS-CHAVE:

Biodiversidade florestal, Cartografia ambiental, Geobotânica, Habitat florestal, Unidade ambiental-paisagística, Valor naturalistico.

\footnotetext{
* Este trabalho foi realizado durante a estadia do Prof. Marcello Martinelli, docente do Departamento de Geografia da FFLCH - USP, junto ao "Dipartimento di Scienze Ambientali - Sezione di Botanica ed Ecologia dell' Universtà di Camerino", do dia 14 de maio ao dia 20 de agosto de 2006 ,
com o auxílio dos fundos de pesquisa científica do Prof. Ettore Orsomando e da "Scuola Internazionale di Dottorato (School of Advanced Studies)" - Diretora: Cristina Micheli, Professora Titular do "Dipartimento di Biologia Molecolare, Cellulare e Animale dell'Ateneo di Camerino.

Os Autores agradecem a gentileza da colega Profa. Dra. Sueli Ângelo Furlan, do Departamento de Geografia - FFLCH - USP, pela acurada revisão da Biogeografia em língua portuguesa. 


\begin{abstract}
:
The municipal territory of Sellano, extended for about $86 \mathrm{sq} \mathrm{Km}$, is located in Umbria (Italy), in the central and eastern part of the region, bordering Marches. It is characterized, from a forestal point of view, for the high value of the index of woodiness -more than $60 \%-$, in comparison with $40 \%$ of Umbria.

The forestal biodiversity is constituted by 7 deciduous natural formations (characterized by Quercus pubescens, Ostrya carpinifolia, Quercus cerris -belonging to the endemic association Carici sylvaticae-Quercetum cerridis, rich in orchids-Quercus cerris and Quercus pubescens, Castanea sativa, Fagus sylvatica and Salix alba) and one artificial formation (Pinus nigra and Pinus halepensis reforestations).

These woods (high forests or coppices with standards), in good state of conservation, surrounded by grasslands and anthropic areas with human settlements, fields and craft zones, characterize 11 environmental-landscape units in comparison with the 42 units of Umbrian landscapes: high hill slopes with Quercus pubescens or Ostrya carpinifolia woods, sometimes alternated to small Bromus erectus pastures, of secondary origin; mountain slopes with Fagus sylvatica woods and small Bromus erectus pastures, of secondary origin; cliffs with chasmophytic formations; high-hill and submountain slopes, with slight inclination, covered by fersiallitic paleosoils, with mesophilous Quercus cerris woods (Carpinion betuli) and Castanea sativa woods of anthropic origin; High hills with Ostrya carpinifolia or Quercus pubescens woods, sometimes alternated to small Brachypodium rupestre pastures, of secondary origin; River valley bottoms with meso-igrophilous Salix alba or Alnus glutinosa woods; tops and slopes with Bromus erectus, Ses/eria nitida or Cynosurus cristatus pastures, of secondary origin; forestal plantations (conifer reforestations), agricultural areas of hills with yearly cultivations; urban rural centres of slopes and mounds; cultivated lands of alluvial plains with yearly cultivations.

The purpose of this study, besides popularizing forestal and landscape biodiversity that characterizes the naturalistic patrimony of the municipality of Sellano, is to contribute, through the geobotanic and landscape study, to the definition of the phyto-microclimatic zone circumscribed in the municipal territory.
\end{abstract}

\title{
KEY WORDS:
}

Forestry biodiversity, Environmental cartography, Geobotany, Forestry habitat, Environmentallandscaped unity, Naturalistic value.

\section{Premissa Introdutória}

A Mesa Redonda sobre o tema "Ambiente e Qualidade" realizada em 23 de julho de 2006 na Sala do Conselho do Município de Sellano, por ocasião da primeira edição da "Mostra Mercado dos Produtos de Qualidade", sob os auspícios da Administração Municipal, foi uma importante ocasião de cotejo cultural sobre a biodiversidade entre os palestrantes participantes, os representantes das instituições municipais, regionais e cidadãos presentes.

Particularmente, o tema - Ambiente e
Qualidade - se destacou, pois as florestas cobrem mais de $60 \%$ da superfície do município de Sellano $\left(85,54 \mathrm{~km}^{2}\right)$, enquanto o índice de cobertura por florestas na Região da Úmbria $\left(8.456 \mathrm{~km}^{2}\right)$ é da ordem de cerca $40 \%$. A mesa redonda foi encentrada sobre o conhecimento, o valor e a conservação da biodiversidade florestal e paisagística do município. Isso, não só para fins florestais e naturalísticos, mas também econômico-sociais, em consonância com os ditames da Conferência das Nações Unidas para o Meio Ambiente e o Desenvolvimento, realizada no Rio de Janeiro, entre os dias 3 e 14 de junho de 1992. 
Argumentar sobre a diversidade biológica florestal e paisagística do município, por parte dos conferencistas convidados (autores desta contribuição), foi bastante simples, pois o território de Sellano foi ilustrado analisando os aspectos ambientais geobotânicos mediante dois estudos significativos: "Carta della Vegetazione del Foglio Foligno" (Orsomando, 1993) e "Carta delle Unità AmbientaliPaesaggistiche dell'Umbria" (Orsomando, Catorci, Martinelli e Raponi, 2000).

O principal objetivo das comunicações apresentadas em 23 de julho, além de dar conhecimento sobre as tipologias das florestas de Sellano, com base científica (propriamente 8 formações, distribuídas segundo as altitudes, em função das peculiaridades abióticas, florísticas, vegetacionais-fitossociológicas e ecológicopaisagísticas), foi aquele de convidar a Administração Municipal - preocupada com o uso produtivo e econômico das florestas - para que ela se certificasse de poder implementar a curto prazo um programa científico-cognitivo e cultural-didático voltado à valorização e conservação do rico e variado patrimônio florestal. Esse é o que torna único e atraente o contexto paisagístico municipal e que está na base da qualidade de vida, não só dos habitantes locais, como também de todas as pessoas que lá acorrem nos períodos estivais e durante os feriados prolongados.

\section{Notas sobre a biodiversidade}

Hoje, por conta das motivações sobre a biosfera, quase todos os problemas sócioeconômicos, históricos, culturais, ecossistêmicos, de gestão e de conservação dos recursos naturais tratam da biodiversidade ou apresentam pressupostos fundamentais sobre o uso e tutela dos componentes vegetais, animais e paisagísticos.

A necessidade de tutelar a biodiversidade no "Planeta Terra" é sempre mais premente e já há alguns decênios constitui um dos objetivos primários, como atestam os acordos intencionais da Conferência do Rio de Janeiro (1992), do Protocolo de Kyoto (1997) e da II Cúpula Mundial Ambiente sobre o Desenvolvimento Sustentável, de Johannesburg (2002), como também as Diretrizes CEE 92/43 "Habitat" e 79/409 "Pássaros".

Conforme a definição da Convenção sobre a Diversidade Biológica do Rio (1992) entende-se por diversidade, "a variabilidade entre os organismos vivos de todo tipo, inclusive, entre outros, os terrestres, os marinhos e aqueles de outros ecossistemas aquáticos, como também os complexos ecológicos dos quais fazem parte. Isso inclui a diversidade, dentro de uma espécie, entre espécies e a diversidade dos ecossistemas".

Pela primeira vez através de acordos globais, as Nações que aderiram às diferentes convenções internacionais têm reconhecido a biodiversidade como um bem insubstituível e de mesmo valor que os recursos como ar, água, petróleo e metais preciosos, devendo ser tutelados em favor das gerações atuais e futuras e, contemporaneamente, têm se conscientizado que a progressiva diminuição da biodiversidade representa uma perda de riqueza natural e cultural incomensurável ao nível mundial.

Em se tratando do tema biodiversidade dirigida ao planejamento e gestão territorial, é certo que a representação cartográfica constitui o elo entre a ciência e o planejamento ambiental e desenvolve um papel determinante quando concebida como documento de síntese, fundamentada sobre a espacialização de processos de derivação do grau de naturalidade, o qual é representado através da situação atual determinada pelas condições ambientais e antrópicas - e avaliada com base na 
composição florística e estrutura ecológica das fitocenoses ou associações vegetais.

Os níveis de naturalidade ou de antropização são estabelecidos medindo-se junto aos aspectos botânicos singulares, a distância que existe entre a situação real e aquela que corresponderia ao estado final da dinâmica ecológica; portanto nas várias fases que compõem o mosaico vegetacional de um território e são representadas sobre um mapa, de acordo com uma ordem crescente de naturalidade, em sistemas que vão desde aqueles antrópicos e artificiais até aqueles seminaturais e naturais.

Para monitorar a biodiversidade, comparecem como basilares os mapas, da vegetação natural atual, da vegetação potencial, fitoclimáticos, das unidades ambiental-paisagísticas, das séries dinâmicas e os mapas dos parâmetros de qualidade naturalística; todos documentos significativos e importantes para um território, não só para informar, mas também para operar uma correta escolha avaliativaplanificadora de conservação compatível com o desenvolvimento socioeconômico.

\section{Mapas Geobotânicos}

Em consonância com o acima declarado, os mapas da vegetação, sejam estruturais de base, sejam temáticos derivados, constituem preciosos documentos científicos e culturais absolutamente indispensáveis no conhecimento do território, para examinar os conjuntos ecossistêmicos de maior valor naturalístico e de maior risco, para empreender um moderno e correto planejamento territorial que respeita as características ambientais, para delimitar as áreas com vocação à gestão e uso dos recursos ambientais e para definir o valor da biodiversidade real, sua proteção e potencial de uso.

Na região da Úmbria, na Itália central, a partir dos anos sessenta, com a contribuição de botânicos da Universidade de Camerino, foi publicada (em escalas e tipologias diferentes) mais de 50 elaborações cartográficas (nada iguais às demais regiões italianas). Elas têm contemplado, ou o território regional inteiro ou limitando-se a municípios, áreas das entidades montanhesas, bacias hidrográficas, parques nacionais ou regionais e biótipos de elevado valor naturalístico (a maior parte destas encontrase relacionada e ilustrada em contribuições específicas, como: Orsomando, 1993; Orsomando e Catorci, 1993; Orsomando et alii, 1999).

Entre estes mapas geobotânicos, como assinalado na premissa introdutória, - mapa "Carta della vegetazione del Foglio Foligno" (Orsomando, 1993) e o mapa "Carta delle unità ambientali-paesaggistiche dell'Umbria" (Orsomando, Catorci, Martinelli e Raponi, 2000) foram utilizados como planos de informação para a representação dos dados florestais e da paisagem ecológico-vegetal do território de Sellano.

\section{Primeira parte}

\section{I- Aspectos ambientais de Sellano}

Os aspectos ambientais de Sellano, que serão apresentados a seguir, com o escopo de fornecer as notas basilares indispensáveis para se obter um quadro mínimo de conhecimentos abióticos, bióticos e ecológicos do território em questão, foram extraídos dos mapas "Hipsometria", "Litologia" e "Pluviometria" (em escala 1:250 000), que constam na lateral esquerda do mapa "Carta della vegetazione del Foglio Foligno" (Orsomando, 1993).

\section{I.I- Localização e posição geográfica}

O município de Sellano, estendendose por uma superfície de $84,54 \mathrm{~km}^{2}$, ocupa 
o setor central oriental da região da Úmbria, na Província de Perugia, fazendo fronteira com o município de Visso, na província de Macerata (Região das Marcas). Ao norte limita-se com os municípios de Foligno, Serravalle di Chienti, Monte Cavallo; ao sul com os municípios de Cerreto di Spoleto, Campello sul Clitunno e Trevi.

Tal território municipal, disposto sobre uma das áreas morfologicamente mais modeladas da dorsal dos Apeninos da Úmbria, se destaca por características naturalísticas, paisagísticas e históricoculturais de grandes predicados. O relevo da porção oriental, com ao centro, em posição panorâmica, o antigo povoado de Sellano, é dominado pelo Vale do Rio Vigi, o maior curso de água afluente do Rio Nera, que por sua vez é tributário do Rio Tibre; aquele da parte ocidental se caracteriza por exibir uma cadeia de relevos calcários muito elevados, enquanto aquele do setor central se destaca por expor áreas mais ou menos planas que formam longas e estreitas gargantas, quase todas atravessadas por antigas estradas.

A peculiaridade geográfica mais evidente do território municipal consiste na sua situação, que se coloca como intermediária entre o Vale Valnerina, ao sul, e os Planaltos de Colfiorito, depressões de origem cársico-tectônica, ao norte, o que fez com que no passado, Sellano representasse um importante entroncamento de itinerários que, através do Vale do Rio Vigi, ligavam Valnerina com Foligno e Camerino e atingiam Spoleto ao longo da antiga Estrada da Spina, via de origem proto-histórica vinculada à transumância. [Fig. 1]

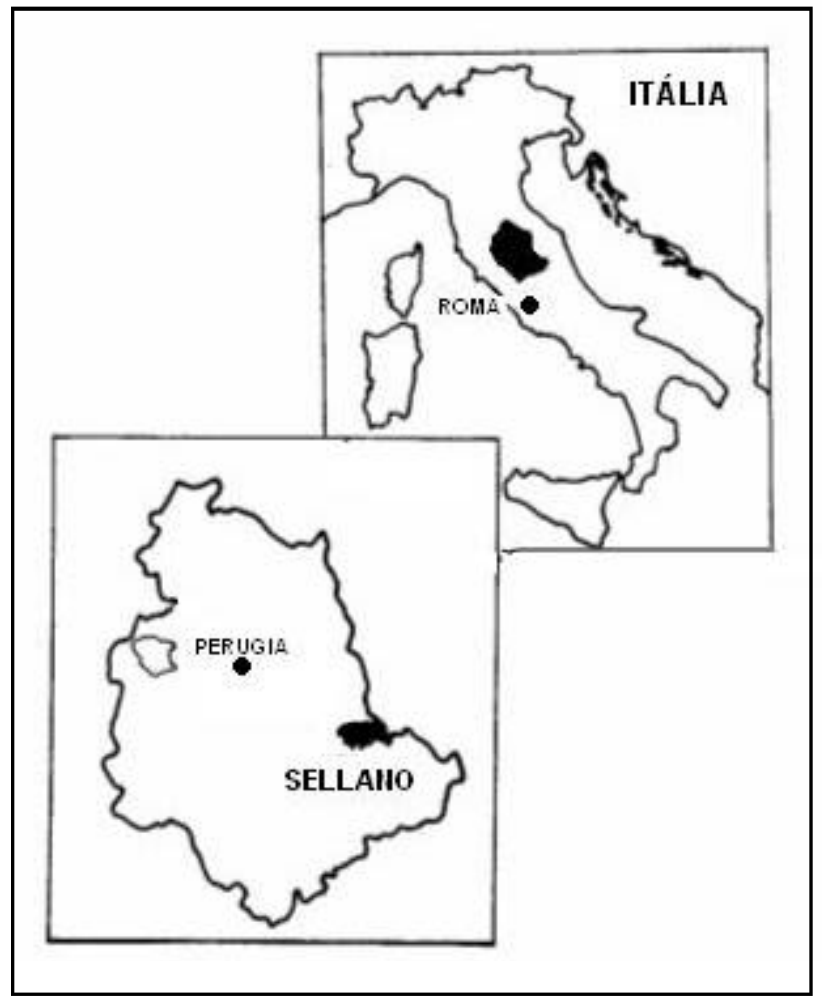

Figura 1-

\section{SELLANO: LOCALIZAÇÃO E POSIÇÃO GEOGRÁFICA}

Sellano localiza-se no setor oriental da Região da Úmbria, situada na porção central do território italiano. 


\section{I.II-Litologia, pedologia e climatologia}

A natureza litológica do território em estudo é constituída basicamente de rochas calcárias sedimentares (do Jurássico) e de margas e margas calcárias (do Cretáceo), que se depositou em ambiente marinho, que pertencem à "Sucessão estratigráfica Umbro-Marchigiana".

Tais substratos carbonáticos, nos diferentes relevos colinares de Sellano estão recobertos por camadas (por vezes com espessura de alguns metros) ou por resíduos de solos relictos denominados "paleossolos", de cor avermelhada com pH ácido, completamente descarbonatados. Sua gênese vincula-se à presença de condições climáticas do tipo tropical-úmido presentes durante os períodos interglaciais pleistocênicos (há cerca de 600.000 anos), enquanto sua conservação se deve a condições morfológicas locais, pois se preservaram melhor sobre os altos topos planos/semiplanos ou no fundo de alguns vales, em geral em trechos de pouco aclive.

Trata-se de solos particulares que constituem um patrimônio paleoclimático e paleogeográfico de apreciável valor naturalístico para o território estudado, como também a presença de alguma peculiaridade florestal que, em especial, interessam às florestas de Carvalho branco descritas adiante.

No que tange ao clima o território municipal apresenta precipitações anuais médias entre 1000 e $1050 \mathrm{~mm}$ e temperaturas anuais médias que oscilam entre 11 e $12^{\circ} \mathrm{C}$, que caracterizam um clima de tipo submediterrâneo, caracterizado por moderada aridez estiva restrita às vertentes muito ensolaradas.

\section{I.III- Morfologia e hidrografia}

O território de Sellano apresenta uma morfologia colinosa e de baixa montanha dos
Apeninos, com partes mais elevadas, também onduladas, que em suas várzeas encerram áreas planas estreitas e alongadas. A maior parte do relevo oscila entre 600 e 1000 metros de altitude; as cotas mais baixas estão um pouco abaixo dos 500 m, comparecem ao longo do Vale do Rio Vigi (que de norte a sul divide ao meio o território municipal), enquanto aquelas mais elevadas, ao entorno de $1300 \mathrm{~m}$, despontam nos topos da dorsal dos Montes Puranno (1296 m), Lagarella (1275), Cima Monte $(1226 \mathrm{~m})$ e Cámmoro (1273 m), que delimitam o município a ocidente.

Tal paisagem morfológica é o resultado de uma série de processos em seqüência que aconteceram na área dos Apeninos a partir do Mioceno seguidos de fases tectônicas alternantes compressivas e de distensão.

A rede hidrográfica superficial, muito articulada, é composta principalmente pelo Rio Vigi e por várias torrentes, fossos e pequenos ribeirões que atravessam de norte a sul o território e pertencem às bacias hidrográficas dos Rios Topino e Nera (afluentes do segmento médio do Rio Tibre). Também as nascentes e fontes, que na grande maioria brotam nas baixadas alveolares, são numerosas e se caracterizam por não apresentarem flutuações estacionais acentuadas em sua vazão. [fig. 2]

\section{II- Habitats Florestais de Sellano}

Certamente, a característica natural mais evidente do território municipal de Sellano é dada pelas formações florestais que constituem um valor excepcional por diversos motivos que podem assim ser resumidos: biodiversidade determinada por 7 formações de caducifólias naturais e por uma artificial (reflorestamentos de coníferas); índice di cobertura arbórea de valor elevado (superior a $60 \%$, um terço a mais daquele da região da úmbria que conta cerca de $40 \%$ ); estado de conservação das florestas 
Figura 2-

SELLANO: RELEVO E HIDROGRAFIA

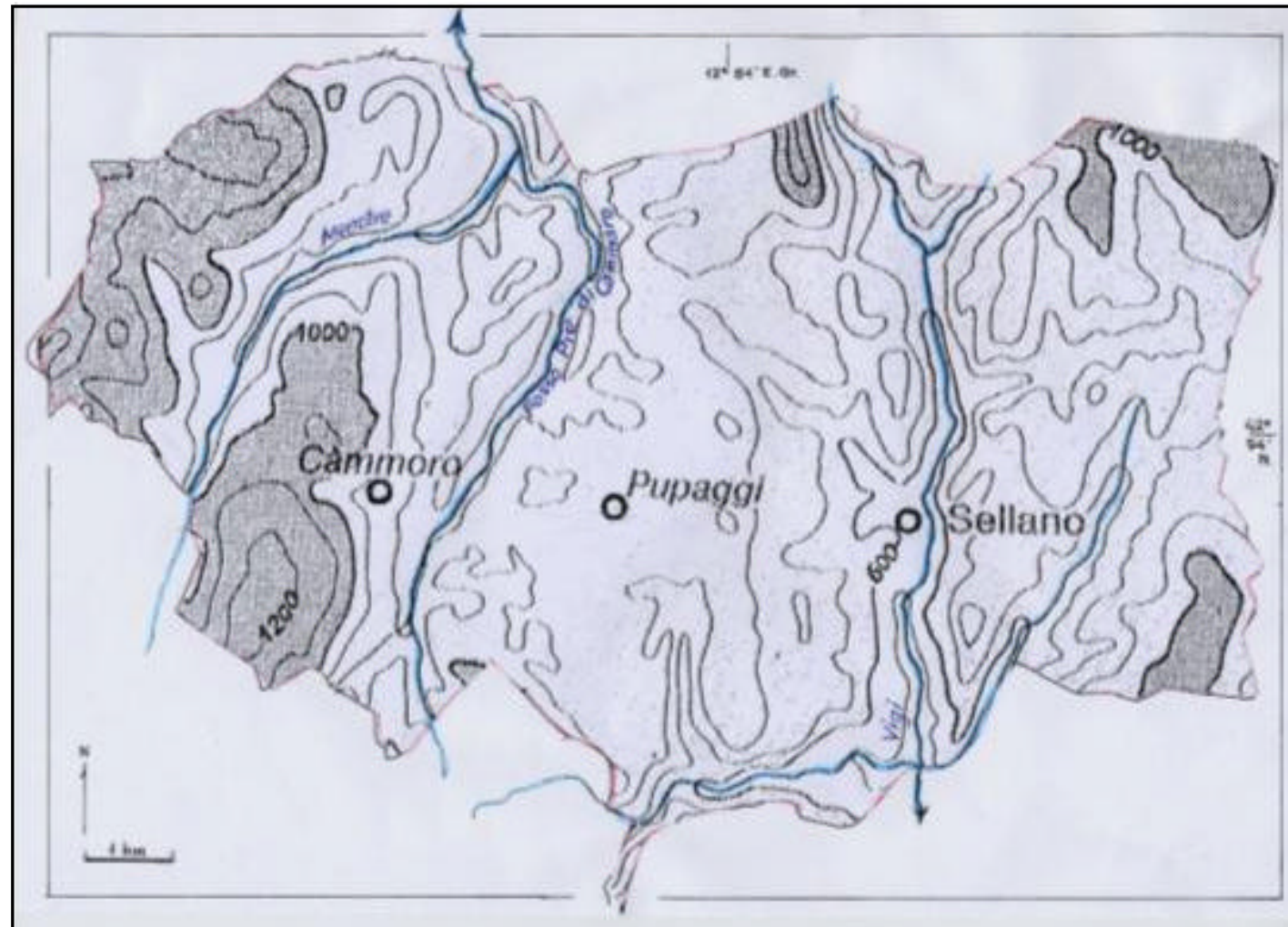

O território de Sellano apresenta uma morfologia colinosa, oscilando entre 480 e 1.296 metros de altitude, banhada por duas bacias hidrográficas principais com drenagem em direções opostas.

muito bom, sendo essas exibidas por indivíduos de alto fuste ou de talhadia; complexo estrutural florestal quase sempre bem representado pelos estratos briofítico, herbáceo, arbustivo (baixo e alto) e arbóreo, junto a unidades paisagísticas diversificadas e de alto valor ecológico; aspectos florístico-vegetacionais e fitossociológicos únicos e significativos; presença de espécies e de habitat contemplados nos "Anexos das Diretivas da CEE". ${ }^{1}$

\section{II.I- Mapa da vegetação da Folha "Foligno"}

Este mapa, em 1:50 000, utilizada para a descrição dos habitat florestais do território em análise, foi realizada por Orsomando (1993) vinculada ao "Programa finalizado" do Conselho Nacional de Pesquisas Italiano (CNR).

Com esse projeto nacional para a Região da Úmbria, foram publicadas até o momento 7 mapas geobotânicos utilizando como bases topográficas as folhas da "Carta d'Italia" do 
"Istituto Geografico Militare" (IGM) (na escala 1:50 000, de formato 20' de longitude por 12' de latitude, articulação segundo o sistema Europeu Unificado de 1950 e superfície média de $650 \mathrm{~km}^{2}$ ). A Folha de "Foligno" tem o código numérico 324 .

Observa-se que este mapa de vegetação (como aqueles das outras folhas) se enquadra na tipologia dos "mapas das séries dinâmicas" segundo os critérios de Ozenda (1964) e Rivas-Martinez et alii. (1985), que colocam em evidência as tendências evolutivas das formações vegetais (estágios) espacialmente contíguos, pertencentes à mesma série e que tendem ao mesmo clímax. Cada série é representada por uma cor (escolhida em função das características ecológicas), enquanto cada estágio é indicado por uma tonalidade dessa mesma cor (que se torna cada vez mais intensa conforme as formações se avizinham do estágio final, o clímax).

Os mapas das séries dinâmicas têm a vantagem de fornecer informações vegetacionais atuais ou reais e, ao mesmo tempo, representar o conjunto vegetacional dinâmico-potencial ou clímax do território objeto de estudo.

Assim, as 8 formações florestais do Município de Sellano, representadas no mapa geobotânico acima citado, são descritas através de breves rubricas ecológico-altitudinais, florísticas, vegetacionais e corológicas, com o acréscimo do valor naturalístico e estado de conservação (muito elevado, elevado e médio). Este foi determinado com base nas conotações naturais já relacionadas e sobre avaliações ligadas aos conhecimentos pessoais adquiridas com trabalho de campo no território de Sellano e naquele regional da Úmbria, que o envolve.

Deve-se advertir que as porcentagens, apresentadas a seguir, foram compiladas dos dados informatizados extraídos do "Annuario delle statistiche territoriali della Regione dell'Umbria" (2000) e que o valor porcentual das florestas caducifólias colinares e montanhosas compreende também os reflorestamentos de coníferas.

\section{II.II- Florestas caducifólias colinares e submontanas}

São constituídas por 5 formações florestais, descritas a seguir, que no conjunto cobrem $57,33 \%$ da superfície de Sellano (ou seja $4.900,06$ hectares) comparados aos 31,88\% da superfície total da Região Úmbria.

\section{II.II.I- Florestas de Carvalhos (Quercus pubescens)}

O Carvalho, com vasta área de ocorrência que se estende entre a Europa meridional e a Ásia Menor (Oriente Médio), na Itália ocorre em todas as Regiões particularmente nas áreas de relevos colinares, sobre as vertentes quentes e secas. É uma espécie xerófila e heliófila e no território de Sellano forma bosques nos lugares mais ensolarados, sobretudo no setor oriental, onde constituem as fitocenoses florestais mais termófilas.

Os bosques de Carvalho que revestem as vertentes dos relevos do Monte Montione (919 m) e do Colle Morro (827 m), nos quais, freqüentemente se desenvolvem junto a outras espécies de caducifólias termófilas, são muito extensos. Na maior parte são geridos pelo abate e às vezes se apresentam abertos e envelhecidos.

Valor naturalístico e estado de conservação: médio.

\section{II.II.II- Florestas de Carpes negros (Ostrya carpinifolia)}

O carpe presente na Europa meridional e a Ásia Menor é uma caducifólia umbrófila, resistente à seca e dotada de ótima adaptabilidade às diversas condições edáficas. No território de Sellano forma bosques que 
Biodiversidade florestal e paisagística do território

municipal de Sellano - Úmbria - Itália, pp. 185 - 211

quase sempre se desenvolvem com outras caducifólias, entre as quais o Freixo (Fraxinus ornus), principalmente nas vertentes colinares e submontanas expostas ao norte e naquelas que formam vales e fossos percorridos por rios e torrentes.

Na área municipal estão distribuídos principalmente ao longo do vale do Rio Vigi, do Fosso Carpineto e sobre os relevos submontanos que circundam o núcleo urbano de Cámmoro. São bosques vinculados ao abate ou ao regime de corte raso e quase sempre apresentam uma estrutura lenhosa homogênea, com cobertura vegetal muito elevada.

Valor naturalístico e estado de conservação: médio.

\section{II.II.III- Florestas de Carvalhos brancos (Quercus cerris)}

O Carvalho branco, com ocorrência na Europa centro-meridional e oriental comparece na Itália em todo o território salvo na Sardenha. É um carvalho caducifólio com fuste quase colunar, que ama viver nos terrenos clásticos, arenosos e frescos, com tendência à acidez.

Em Sellano os bosques de Carvalho branco representam as fitocenoses florestais monoespecíficas mais difundidas e ocupam a parte central do município caracterizada por relevos colinares com cristas arredondadas e semiplanas. A presença destes bosques acidófilos e mesófilos, sobre substrato calcário, é estreitamente ligada à camada de paleossolos pleistocênicos que o recobrem em superfície. Pela peculiaridade edáficas e climáticas estes bosques, estudados pela primeira vez pelos botânicos Orsomando e Catorci no mês de Junho de 1987 (Orsomando, 1993; Catorci e Orsomando, 2001) e nos anos sucessivos, sempre pelos mesmos autores, em localidade limítrofe (Planaltos de Colfiorito) foram enquadrados em uma nova associação fitossociológica ${ }^{3}$, na qual estão presentes as Orquídeas Platanthera chlorantha, Platanthera bifolia, Neottia nidus-avis, Cephalanthera rubra, Cephalanthera damasonium, Cephalanthera longifolia, Dactybuhiza m aculatae Limodorum abortivum, das quais a primeira (junto a outras espécies) é considerada característica local e diferencial da associação, enquanto as demais estão também difundidas por todo o território de Sellano.

Valor naturalístico e estado de conservação: muito elevado.

\section{II.II.IV- Florestas de Carvalhos brancos (Quercus cerris) com Carvalhos (Quercus pubescens)}

Trata-se de fitocenoses mistas que em relação às florestas apenas de Carvalho branco apresentam uma maior termofilia devida seja a fatores de exposição (baixas vertentes voltadas a leste, oeste ou quase ao sul) seja a condições edáficas.

No território de Sellano se desenvolvem às bordas das áreas recobertas por paleossolos, em âmbitos onde os solos relictos são conservados em finas camadas que se sobrepõem aos substratos calcários com afloramentos de margas e margas calcárias. Particularmente extensos são os bosques de Carvalho branco com Carvalho no setor norteoriental da área de estudo, que circundam os núcleos rurais de Peneggi, Piaggia e Renaro.

Valor naturalístico e estado de conservação: médio.

\section{II.II.V- Florestas de Castanheiros (Castanea sativa)}

O Castanheiro, provavelmente originário da Europa oriental e da Ásia Menor, apresenta uma área de distribuição primitiva que é muito difícil de ser reconstituída porquanto a espécie, historicamente conhecida como planta florestal, foi sempre amplamente cultivada e, portanto intimamente relacionada à ação secular do homem. $\mathrm{O}$ indigenato do Castanheiro na Itália 
é ainda muito discutido, mas a maior parte dos castanhais (presentes também em áreas remanescentes com árvores seculares) quase sempre é de origem antrópica.

$\mathrm{Na}$ área municipal de Sellano os bosques de castanheiros estão distribuídos ao sul da vila de Forfi e ao longo da pequena dorsal que vai da aldeia de Sterpare até o Monte Puriggia (900 $\mathrm{m})$. Na maioria são castanhais com a presença de árvores para a produção de frutas. Castanheiros seculares isolados ou alinhados em renques, que delimitam áreas cultivadas ou pastoris em volta dos pequenos núcleos rurais, constituem elementos paisagísticos singulares.

Valor naturalístico e estado de conservação: muito elevado.

\section{II.III- Florestas caducifólias montanas}

São representadas somente pelos bosques caducifólios de Faia que ocupam 203,90 hectares de superfície municipal, correspondente ao valor de 2,39\%, enquanto o índice da Úmbria é de 1,57\%.

\section{II.III.I- Florestas de Faias (Fagus sylvatica)}

A Faia, espécie mesófila e oceânica, encontra-se distribuída pela Europa e Ásia ocidental. Na Itália vive em todas as Regiões com exceção da Sardenha. É a espécie florestal mais significativa das zonas montanhosas dos Apeninos, onde, nas partes altas, forma bosques quase puros ou consorciados com 0 Abeto branco e nos sopés, bosques mistos com caducifólias submontanas.

Nos relevos de Sellano ocupam as vertentes calcárias mais elevadas, acima dos 1000 metros de altitude particularmente no setor montano ocidental dos Montes Puranno (1296 m) e Cámmoro (1273 m). Já nas vertentes orientais, os bosques de Faias estão presentes, em altitudes inferiores (entorno aos $900 \mathrm{~m}$ ), somente nas localidades de Madonna del Monte e Fonte L'esca. Na maioria, trata-se de florestas puras, às vezes misturadas aos Carpes e a diversas espécies de Bordo, destinadas a corte com núcleos de alto fuste nas vertentes sombreadas e nos talvegues.

valor naturalístico e estado de conservação: muito elevado.

\section{II.IV- Florestas higrófilas ciliares}

Recobrem 37,00 hectares da superfície municipal, ou seja os $0,43 \%$, enquanto o índice da Úmbria é 0,83\%.

\section{II.IV.I- Florestas higrófilas de Salgueiro branco (Salix alba) e moitais de Salgueiros de espécies variadas (Salix sp. pl.).}

O Salgueiro branco é uma espécie com ampla difusão na Europa, Ásia e África e na Itália comparece em todo o território, onde prefere terrenos clásticos e frescos. É uma espécie higrófila que amiúde se associa ao Álamo negro (Populus nigra) e comumente divide o espaço ecológico com outras espécies arbustivas altas e baixas de Salgueiros, formando faixas de moitais.

No território de Sellano os bosques e moitais de Salgueiros com Choupos (muito comuns são os Choupos da Itália - Populus nigra var. italica - facilmente reconhecíveis pelo perfil colunar e fino) margeiam quase que completamente os maiores cursos de água, como o Rio Vigi e o Fosso di Fauvella, enquanto nos outros rios se desenvolvem somente em pequenas e faixas descontínuas. Ao longo das margens do Rio Vigi e adjacentes aos bosques de Salgueiros, são dignos de nota os núcleos de Amieiros (Alnus glutinosa) e os planos recobertos de espécies do gênero Carex, misturados aos bambuzais dos brejos (Phragmites australis).

Valor naturalístico e estado de conservação: elevado. 
Biodiversidade florestal e paisagística do território

municipal de Sellano - Úmbria - Itália, pp. 185 - 211

\section{II.V- Florestas artificiais}

Sob esta denominação estão incluídas as formações florestais introduzidas, há mais de um século, pelo homem em áreas de pastagens, arbustivas e com bosques ralos muito degradadas e danificadas, onde o impacto antrópico era considerado quase irreversível.

\section{II.V.I- Reflorestamentos de}

\section{Coníferas}

Os reflorestamentos foram introduzidos nas áreas degradadas da série vegetacional dinâmica do Carpe negro e do Carvalho branco e, implantados na maioria das vezes mediante o emprego do Pinho preto (Pinus nigra) e Pinheiro de Alepo (Pinus halepensis), aos quais foram associadas outras coníferas dos gêneros Cipressus e Cedrus.

Os reflorestamentos que recobrem as zonas mais elevadas do Monte della Piaggia (963 m) e do Monte Siliolo (1071m) são os mais extensos.

\section{Segunda parte}

\section{III- Ambiente e Paisagem}

\section{III.I- Notas sobre natureza e sociedade}

$\mathrm{Na}$ época pré-socrática (século $X$ a.C.) o homem integrava a natureza. Era uma só coisa. Esta era a totalidade de tudo o que compunha a existência. Era a Physis. A ela pertencia o céu, a terra, a pedra, a planta, o animal, o homem com suas elaborações e seus feitos, além dos deuses.

Mais tarde, com Platão e Aristóteles (séculos IV e III a.C), o homem e a idéia se valorizaram. A natureza passou a ser uma natureza não-humana.

Porém maior afirmação da oposição homem-natureza se deu por conta da influência judaico-cristã.
Tal oposição se consolidou ainda mais com Descartes (século XVII), que estruturou todo o pensamento, o qual acabou chegando até os dias atuais. Passou-se a ver a natureza como um recurso, sendo o seu conhecimento útil à vida, e ao homem como o centro do mundo, sendo considerado sujeito em oposição ao objeto.

No Iluminismo do século XVIII, em plena afirmação do capitalismo, a realidade teve que ser compreendida, deixando de lado dogmas religiosos.

No século XIX a civilização capitalista industrial cristalizou a visão de um mundo com uma natureza objetiva e exterior ao homem. Assim, as ciências do homem se separaram das ciências da natureza. Serão a Ecologia e os hodiernos movimentos ecológicos e outras idéias mais atuais a promover e forjar novas concepções de mundo mais integradas.

A visão unificada da realidade proporcionou a compreensão dialética das relações entre homem e natureza, superando a questão da dualidade.

Com o advento da "Teoria Geral dos Sistemas" proposta por Bertalanffy na década de 1950, sistematizou-se uma concepção integrada da realidade. A ecologia foi a primeira área de estudo a absorvê-la. Nessas bases teóricas em 1935, Tansley criou o conceito de Ecossistema. (Bertalanffy, 1968).

O primeiro pesquisador a trabalhar nesta concepção foi o russo Sotchava em 1962, propondo um método de estudo para a geografia física - o Geossistema: "geossistema é a expressão dos fenômenos naturais, ou seja, o potencial ecológico de determinado espaço no qual há uma exploração biológica, podendo influir fatores sociais e econômicos na estrutura e manifestação espacial, porém, sem haver necessariamente, face aos procedimentos dinâmicos, uma homogeneidade interna". (Sotchava, 1976).

Em 1968, Bertrand propôs o estudo da paisagem, o qual seria feito no âmbito de uma 

\& ORSOMANDO, E.

geografia física global. A paisagem não é a soma de elementos geográficos. É, numa determinada porção de espaço, o resultado da combinação dinâmica, portanto instável, de elementos físicos, biológicos e antrópicos que, reagindo dialeticamente uns com os outros, fazem da paisagem um conjunto único e indissolúvel, em perpétua evolução. o mesmo autor, ao considerar a questão taxonômica da paisagem, elegeu a unidade "geossistema" como a escala adequada à manifestação da maior parte dos fenômenos que mais interessam para os estudos geográficos. Seria a escala ideal por ser compatível com a escala espaço-temporal do homem.

Um outro campo de pesquisa muito próximo às temáticas do ambiente, da paisagem, e da ecologia foi o da Ecologia da Paisagem proposto por Troll em 1966, visto como ciência da estrutura e do funcionamento da paisagem.

Com as contribuições da geobotânica em base fitossociológica, as pesquisas sobre a paisagem reconheceram no espaço, não apenas as associações vegetais unitárias, mas também as respectivas séries de vegetação. (Tuxen, 1956; Gehu, 1991).

Uma outra visão integrativa é a proposta da Ecodinâmica feita por Tricart (1977), que é o estudo da paisagem no seu comportamento dinâmico. Um pouco mais tarde, surge a proposta da Ecogeografia formulada pelos naturalistas Tricart e Kilian (1979), voltada ao planejamento do ambiente.

No presente momento da história da sociedade humana, o modo de produção capitalista, hoje hegemônico em todo o mundo, instituiu a natureza em clara oposição ao homem e vista como objeto, fonte inesgotável de recursos para a sociedade, com o risco porém de determinar desastrosos inconvenientes para o ambiente.

Nas décadas de 1960 e 1970 constatouse uma crescente conscientização atinente a uma natureza que teria seus recursos esgotáveis e, portanto, com possibilidade de se prever um desenvolvimento que resultaria insustentável frente a um crescimento econômico sem controle.

$\mathrm{Na}$ visão do materialismo histórico e dialético, na busca da integração, a relação entre o homem e a natureza se faz mediante uma mediação operada pelo trabalho dos homens, membros de uma sociedade, dispondo de determinadas relações sociais historicamente definidas. Entretanto, o capitalismo industrial de hoje converteu o trabalhador em objeto, alienando-o de seus produtos, dos meios de fabricá-los e da própria natureza a que tem direito, não obstante ele ser também natureza.

Apesar disto, é bom lembrar que desde o aparecimento e desenvolvimento do homem, o que se deu no meio natural, a história da humanidade é a continuação da história da natureza, havendo, assim, uma interação dialética, confirmando o homem como ser natural, porém emergindo, como ser social. Há assim, reciprocidade. (Marx e Engels, 1979).

O que a sociedade produz a partir da natureza passa a participar da história humana, acontecendo em seu espaço e tempo.

Desde o século XVI a ciência e a técnica sempre intervieram na natureza com finalidades sempre mais práticas e econômicas, na busca da uma melhoria da vida humana. Até mesmo se com sintomas brandos, emergentes desde o fim do século XIX, no auge da "Segunda Revolução Industrial", a questão ambiental eclodiu somente após a Segunda Guerra Mundial, suscitando novas considerações acerca da realidade. A sociedade se conscientizou da característica finita dos recursos naturais e começou a questionar os progressos científicos e tecnológicos concebidos e promovidos principalmente nos últimos tempos. Confirmamse assim novas concepções, como as "redes ecológicas", a "biodiversidade" e o "desenvolvimento sustentável". 


\section{III.II- Estudos acadêmicos}

Estudos científicos de todo tipo são feitos na academia com o objetivo de resolver os problemas que afligem a humanidade. No campo dos estudos ambientais, entre outros modos de apresentar os resultados das pesquisas, pode-se considerar aquele que se apresenta sob a forma de mapa, com a representação das unidades espaciais sintéticas, de pronta aplicabilidade prática no planejamento do território. Estas unidades espaciais sintéticas, que podem ser chamadas de "unidades ambientais", "unidades de paisagem" ou "unidades ambientalpaisagísticas", são áreas que se incluem num conjunto coeso de ecossistemas interagentes e distintos por aspectos di singularidade peculiar.

As pesquisas acerca o ambiente colocam desde o início a questão sobre o que é o ambiente. Pode-se afirmar que é o entorno; que é tudo o que circunda cada ser ou pessoa; que é o conjunto das condições físico-químicas e biológicas, nas quais é possível o desenvolvimento da vida dos seres vivos, inclusive o homem.

Uma das primeiras definições, dos anos 1920, dizia que o ambiente se constituía nas condições naturais (físicas, químicas e biológicas) e culturais (sociológicas) capazes de agir sobre todos os organismos vivos e as atividades humanas. Nos anos de 1960 o vocábulo adquiriu uma definição mais completa e abrangente: "recursos naturais bióticos (flora e fauna) e abióticos (ar, água, solo) e suas interações recíprocas, as características da paisagem e os bens que compõem a herança cultural".

Uma definição mais social, para os dias de hoje seria: "ambiente é o meio físico, seja natural como construído, no qual um indivíduo ou um grupo vive, incluindo o ar, a água, o solo, o subsolo, a flora, a fauna, mais os seres humanos, e suas inter-relações".

Pode-se dizer, também, que o ambiente é uma entidade holística. É uma integração desejável da totalidade das variáveis abióticas e bióticas que correspondem aos elementos que ele congrega.

O Grupo de Trabalho Conjunto da ACI/ UGI, em 1980 considerou o ambiente como aquelas circunstâncias geográficas que influenciam (preservam, melhoram ou degradam) o sistema ecológico-humano.

Hoje, o ambiente é considerado como um conjunto integrado com o qual as comunidades humanas travam relações e diante do qual elas se colocam numa relação dialética feita de ações e reações, nas quais participam todos os elementos do ambiente circundante. Estudar a natureza significa estudar a historia natural da Terra procurando compreender sua gênese e as transformações que se produziram nos deferentes ecossistemas.

\section{III.III- Notas sobre o significado de paisagem}

Nos estudos do ambiente, surge uma entidade que deve ser apreciada com primor: a paisagem. É o que se vê num lance instantâneo do olhar.

A cultura da paisagem é antiga. Parece que teria surgido no oriente nos primeiros séculos da era atual. Teria se iniciado como um culto a uma estética paisagística, presente na literatura, na pintura, nos jardins. Naqueles tempos, seja na China como no Japão, a pintura da paisagem não fazia parte do pano de fundo, mas se colocava no primeiro plano, numa clara demonstração de sólido relacionamento com os personagens presentes no quadro. Nessas culturas, o homem se reconhecia como ser social em estreita comunhão com a natureza.

$\mathrm{Na}$ busca de uma visão de mundo, exterior aos cânones teológicos, o ocidente encontrou um novo interesse pela natureza através da pintura da paisagem. Com isso, as pessoas passaram a contemplar a natureza com outros olhos, buscando o prazer pelo belo. Essa visão teria se desenvolvido no Renascimento, 
antes na Holanda, por volta de 1415 , depois na Itália, confirmando-se com a pintura paisagística da segunda metade do século XV. Em contraste com o oriente, nesta outra parte do mundo, o homem se identificava como tendo que enfrentar a natureza e até mesmo opondo-se a ela. Distinguem-se, assim, pinturas de paisagens que consideram o caráter selvagem da natureza e aquelas que a concebem como uma arte de jardinagem. Na primeira, a natureza frente ao homem se mostra ameaçadora e na segunda, se sujeita a ele.

Já Leonardo da Vinci (1452 - 1520) apreendia a paisagem num sentido mais completo, tomando todo cuidado de abordá-la antes em base científica, depois em base estética.

Nessa mesma direção, os naturalistas do início do século XIX, elevaram o conceito de paisagem a uma acepção científica sustentada pela definição de Alexander von Humboldt de 1846, que afirmava que a paisagem deveria abranger a totalidade das peculiaridades de um território (Ingegnoli, 1993). Em prosseguimento à declaração de Humboldt, pôde-se admitir instituída para a Geografia, a definição de paisagem, aquela de Paul Vidal de La Blache: trata-se do resultado das ações dos homens se adaptando ao seu ambiente natural, no percurso da história.

Na Rússia (ex URSS), a ciência da paisagem, com uma preocupação mais epistemológica e teórica, teve respeitável reconhecimento entre os estudiosos do país e estrangeiros. Deve-se atentar que esta orientação vinha sendo lucubrada desde o fim do século XIX por parte de Dukutchaev, com sua escrupulosa atenção dada às paisagens. Com o "Complexo geográfico natural", o cientista já mostrava uma preocupação sobre a estrutura e funcionamento da paisagem. A partir dessa postura passou-se, depois, nos anos sessenta, ao geossistema por obra de Sotchava (1976).

Para Sotchava o geossistema é um sistema natural em nível local, regional ou global, num âmbito onde o substrato geológico, solo, comunidades bióticas, água e correntes atmosféricas são envolvidas em intercâmbios recíprocos de matéria e energia no interior de um conjunto particular.

Forman e Godron (1986), no entanto, definem a paisagem como: porção de território heterogênea composta por um aglomerado de ecossistemas interagentes que se repete com estrutura reconhecível.

Aquela de Ingegnoli (1993) se apresenta como adequada a evidenciar toda sua complexidade: é um sistema de unidades espaciais ecologicamente diferentes, interrelacionadas entre si, isto é, configurando um sistema de ecossistemas ou um metaecossistema.

A paisagem não expõe apenas o que lhe é dado pela natureza; incorpora resultados da cultura, ao mesmo tempo em que a compõem. Assim, ela não está fora do contexto social em seu movimento histórico; o integra com seus valores, com suas representações e seus símbolos.

Paisagem é a expressão fisionômica do espaço geográfico que se observa. Constitui o cenário da existência de cada um. Desta feita, seu conceito é impregnado de conotações culturais e ideológicas. Vários componentes intervêm no momento de se captar sua imagem.

Deste modo, ela não pode ser vista apenas na expressão material da natureza e da sociedade, mas também, na sua essência, vale a dizer como uma elaboração social e cultural, dotada, portanto, de vida humana. Assim, sua compreensão mais completa se dará mediante sua concepção como espaço geográfico. Tornar-se-á assim, manifestação mais envolvente da realidade considerada como totalidade social contida no arranjo espacial de seus componentes, na respectiva territorialidade. (Santos, 1994).

O Professor Milton Santos (1994) faz uma oportuna consideração a respeito da paisagem. Paisagem é a porção da configuração territorial que é possível abarcar com a visão. Essa dimensão 
Biodiversidade florestal e paisagística do território

municipal de Sellano - Úmbria - Itália, pp. 185 - 211

do visível, material, estética é a forma. O espaço é o conjunto das formas mais a vida que as anima. Há um contexto de objetos e ações.

A apreciação panorâmica da paisagem tem como visão inicial, aquela frontal tomada do chão, fornecendo uma seqüência de silhuetas desdobradas em planos verticais que se subseguem em profundidade. O jogo desses planos organiza a visualização da paisagem numa série contínua de escalas que vão diminuindo em direção ao horizonte, ao mesmo tempo em que se interpõem recortes que encobrem parte do conjunto espacial que fica por detrás. (Lacoste, 1977; Lecoeur, 1987; Cullot, 1986).

Paisagem é imagem. No final do século XIX, a fotografia transferiu a paisagem da tela do pintor, disponível para poucos, para a imagem revelada que se reproduz em muitas cópias, acessível a um público maior.

Frémont (1995) propõe uma questão muito sábia: "...mas quem vê a paisagem?..." Pode-se constatar que os componentes de uma mesma paisagem são percebidos de maneiras distintas pelas pessoas. Assim, haverá uma paisagem para o geógrafo, o turista, o naturalista, o planejador, o ecólogo e o fitossociólogo.

Para o geógrafo, desde o fim do século XIX, a paisagem é um objeto de estudo. Ela é descrita e analisada, porém com uma visão mais voltada para um inventário raciocinado, sem considerar a estética e a maneira como é apreendida ou interpretada.

A paisagem do turista se coloca, seja como o apreciar de uma porção do espaço concreto, seja como vislumbrar um espetáculo. Ele tira uma fotografia para comprovar que esteve no lugar.

Para o naturalista, a paisagem consiste num território a ser preservado como testemunho das interações recíprocas entre o ambiente e as atividades da sociedade em tal espaço.

Para o planejador, a paisagem, devido seu valor natural e cultural, é uma realidade que se coloca como objeto de gestão do território numa visão prospectiva.

O ecólogo vê a paisagem como um nível de organização dos ecossistemas, onde se apresentam e se equilibram certo número de processos ecológicos.

Para o fitossociólogo ela constitui uma unidade ecológica dinâmica em estrutura e função, formada por um mosaico de elementos interligados pela comum tendência dinâmica em direção a uma mesma tipologia de vegetação madura (Blasi et alli., 2003).

Recentemente, o Conseil de l'Europe, na "Convention européenne du paysage", realizada em Florença no ano de 2000, definiu a paisagem como: "Uma porção de território tal como é percebida pelas pessoas, onde sua característica resulta da ação dos fatores naturais e/ou humanos e de suas interações" (Frémont, 1995; Godart e Deconinck, 2003).

\section{III.IV- Cartografia ambiental da paisagem}

Hoje, a cartografia é considerada como um setor científico voltado à "difusão, representação, comunicação e uso da geoinformação nas formas, visual, digital ou tátil, que inclui todos os processos de tratamento de dados, de elaboração e de estudo de qualquer tipo de mapa".

No presente momento, a cartografia, também, não pode ser vista fora da era da informação de onde desponta como conceito central, aquele de "visualização cartográfica", considerado como forma de amalgamar os raciocínios sobre a cartografia associados à cognição e análise, à comunicação e às tecnologias computacionais. (Taylor, 1994).

Foi a crescente especialização e diversificação das realizações no âmbito da cartografia científica que, procurando atender as necessidades aplicativas solicitadas pelos diferentes ramos de estudo sistematizados com a divisão do trabalho cientifico, no fim do século XVIII e principio do século XIX, instituiu um outro tipo de cartografia, a cartografia temática, domínio dos mapas temáticos. (Palsky, 1996).

Do ponto de vista metodológico, a cartografia, como também seu ramo temático, pode ser também conjeturada dentro de uma visão 
estruturalista. Nesta linha, seria concebida como uma linguagem gráfica: a da Representação Gráfica. Neste sentido, a cartografia tem como principal propósito transcrever as três relações fundamentais entre os elementos que compõem a realidade que se apresenta ao cartógrafo através de relações visuais de mesma natureza:

- a diversidade entre elementos será transcrita através da diversidade visual,

- a ordem entre elementos será transcrita através da ordem visual,

- a proporcionalidade entre elementos será transcrita através da proporção visual.

Para sistematizar estas relações visuais como representações gráficas da realidade no mapa, devem-se conhecer as variáveis visuais e suas propriedades perceptivas.

Congregando essas proposições, a cartografia temática conta com vários métodos para a representação do conteúdo de um ou um conjunto de fenômenos, contemplados num determinado tema. Estes métodos de representação, hoje bem conhecidos e difundidos, se estabeleceram a partir de uma evolução lenta e progressiva de elaborações em atendimento às exigências dos diferentes ramos científicos, cada um na sua especialidade.

Dentre os métodos de representação haverá aquele mais adequado às características e às formas de manifestação dos fenômenos considerados em cada tema, seja na apreciação estática como dinâmica coerente com as abordagens, qualitativa, ordenada ou quantitativa. Além do mais, o desenvolvimento do raciocínio a ser mobilizado nas representações da realidade pode ser empreendido em dois patamares, de análise e de síntese. Por fim, no momento da aquisição do conteúdo, o mapa pode oferecer dois níveis básicos de leitura e interpretação: elementar e de conjunto.

São várias as propostas metodológicas para se chegar à cartografia ambiental da paisagem; entre as mais recentes podem-se considerar aquelas de Pedrotti et alii. (1997) e Pedrotti (1998; 2004), onde a cartografia ambiental é entendida como a representação integrada de fatores ecológicos, presentes e operantes, com o fim de se obter uma compreensão holística do ambiente.

Para alcançar estes resultados podem-se seguir como sugere Pedrotti, várias etapas: 1 identificação de áreas unitárias singulares homogêneas do ponto de vista tectônico, litológico, climático, geomorfológico (nas várias formas de relevo resultantes de processos específicos), morfométrico (altitudes, declividades, exposições), pedológico, vegetacional (vegetação natural, potencial e das tendências dinâmicas) e faunístico; 2 - levantamento das séries de vegetação (vegetação real) de cada área elementar; 3 reconhecimento dos processos ecológicos dinâmicos que interessam as associações vegetais da série; 4 - subdivisão ou agrupamento das associações que compõem a série, frente ao uso mais ou menos intenso do território, por conta da presença do homem; 5 - delimitação e registro sobre uma base topográfica conveniente, destas subdivisões ou agrupamentos reconhecidos como tipos de unidades ambientais.

Cada etapa é definida por uma proposição que torna evidente as mais notáveis características naturais e sociais do ambiente, entendido naquelas unidades, segundo um raciocínio holístico. As unidades ambientais podem ser reunidas e inseridas em vários níveis de categorias superiores de uma apropriada proposta de classificação hierárquica.

Pedrotti (2004) também prescreve diretrizes para a cartografia ambiental através de orientações geossinfitossociológicas. Assim, pode-se passar das unidades (séries e cadeias) da cartografia geossinfitossociológica às unidades ambientais. Essas unilades sãoheterogêneas, quando são vistas em base ecológica que reúnem ecótopos e revelam identidades distintas. A hom ogeneidade se encontraria som ente no plano fincional, quando se controly o uso que a sociedade concuz no território.

\section{III.V- Tipologias paisagísticas}

Em tempos mais recentes, os estudiosos do ambiente, das paisagens e de suas cartografias sugerem se estabelecer 
um sistema hierárquico das unidades espaciais divisadas em vários níveis de organização. Esta alusão visa obter-se uma clara e ágil articulação das unidades territoriais, oferecendo à representação sobre o mapa, a possibilidade de se entrever as possíveis relações entre elas, ao mesmo tempo, de se controlar suas interconexões com os níveis mais altos e mais baixos da classificação.

Pode-se anunciar que existem vários critérios e métodos de classificação da paisagem. Ingegnoli (1993) lembra que, mesmo esses métodos não sendo convergentes em algumas partes, podem ser complementares. A título de exemplo, para o caso da cartografia das paisagens da Itália, em escala pequena, o Autor propõe uma classificação das unidades de paisagem em vários níveis:

$$
\begin{aligned}
& 1^{0} \text { nível - Regiões biogeográficas, } \\
& 20 \text { nível - Sub-regiões biogeográficas, } \\
& 3^{0} \text { nível - Sistemas paisagísticos, } \\
& 4^{\circ} \text { nível - Subsistemas paisagísticos. }
\end{aligned}
$$

\section{Terceira parte}

\section{IV- Ambientes paisagísticos da Úmbria}

\section{IV.I- Mapa das unidades ambiental- paisagísticas}

Essa representação paisagística da Úmbria, composta na escala 1:100 000 por Orsomando, Catorci, Martinelli e Raponi (2000) se apresenta como um mosaico de áreas paisagísticas típicas evidenciadas por cores distintas, constituindo uma elaboração geobotânica de síntese, na qual não se tem mais a representação individual dos aspectos abióticos (geológicos, geomorfológicos, pedológicos, altitudinais, hidrográficos e climáticos) e bióticos (florísticos, vegetacionais, paisagísticos e antrópicos) que caracterizam o ambiente da Úmbria, mas sim uma integração de elementos da natureza e da sociedade que individualizam áreas territoriais ecologicamente homogêneas denominadas "unidades ambiental-paisagísticas".

No levantamento e definição das citadas unidades ecológicas, que resultaram em 42 , os mapas da vegetação atual e potencial da Úmbria, bem como os mapas regionais da litologia e do fitoclima, constituíram uma consistente fonte de informações.

Em particular, as 42 unidades (referenciadas às grandes categorias de paisagem vegetal natural, seminatural e antrópica ou cultural, definidas mediante a análise das séries de vegetação e através da "distância" entre a vegetação natural atual e aquela potencial) são distribuídas em 8 "sistemas geológicos" (calcários, margosos, calco-margosos, areno-margosos, arenosos, argilo-arenosos, etc.) e em 15 "conjuntos ambientais" (colinares montanos, altoapeninicos, das bacias cársticas de origem tectônica, das áreas com paleossolos, etc.).

$\mathrm{Na}$ avaliação da situação da condição ambiental da Úmbria, esse mapa, fruto de um estudo multidisciplinar, adquire um notável valor, pois permite avaliar concretamente a "distância" entre o estado da vegetação existente nas diversas unidades ambientais e aquele correspondente ao seu máximo valor de naturalidade. São exemplos, os casos da vegetação primária relativa às florestas e da vegetação de origem antrópica referentes às culturas agrárias ou às áreas urbanizadas.

\section{IV-II- A organização de um mapa paisagístico}

A identificação das unidades de paisagem considerou o reconhecimento dos componentes da realidade de forma integrada. Levou em conta a tectônica, o relevo, a hidrografia, o clima, os solos, a vegetação, o uso agrícola do território e outros usos decorrentes de manifestações da atividade humana, através do tempo, assim como a análise das várias 
relações entre sociedade e natureza que modelam uma materialidade múltipla.

Essas orientações são consoantes com as propostas metodológicas colocadas pela literatura científica selecionada, que considera as paisagens, tanto apreendidas em escalas para amplas extensões, como para áreas exíguas, exprimindo a unidade e a identidade de cada lugar, refletindo a história natural e cultural de um território, em certo momento da reprodução da sociedade. A essa visão integrada acrescenta-se o contínuo dinamismo, seja da natureza, seja da sociedade, que se manifesta também como único para cada setor espacial.

Tomando-se por base os estudos feitos por vários autores em diversos campos científicos, se mostrou como pertinente, dentro da hierarquia das paisagens, o nível escalar espaço-temporal do geossistema (Bertrand, 1968).

Como última etapa dessa elaboração devese entrar no domínio do raciocínio de síntese, o qual estabelecerá sobre o mapa as unidades de paisagem, unidades sintéticas que corresponderão a agrupamentos de elementos unitários e singulares de espaço caracterizados por agrupamentos de atributos que a pesquisa individualizou. Essa cartografia se concebe como ambiental, portanto de síntese, uma vez que as unidades de paisagem se apresentam como geossistemas, dotados de morfologia, funcionamento e comportamento (Beroutchachvilli e Bertrand, 1978; Ferreira, 1997; Martinelli, 1999; Pedrotti e Martinelli, 2001).

A organização da legenda do mapa terá que dar transparência às premissas metodológicas assumidas para o estudo, como também a todo o raciocínio desenvolvido para alcançar a representação das unidades de paisagem. Nesse sentido, por exemplo, será ideal adotar uma disposição de legenda que contemple uma ordem taxonômica com vários níveis de categorias. Esses podem variar em número segundo a escolha de determinado tipo de classificação por parte do pesquisador. Considera-se o caso de quatro níveis.

Num primeiro nível, colocam-se os grandes agregados de unidades de paisagem escalonados desde os mais naturais até os mais artificiais, isto é, culturais produzidos pela sociedade humana.

Num segundo nível, considera-se no interior de cada agregado de primeiro nível, o arranjo de conjuntos de paisagens ancorados em sólidas bases estruturais e litológicas.

No terceiro nível exibem-se incluídos em cada arranjo de segundo nível, agrupamentos de paisagens distinguidos por características do relevo associadas com aquelas fitoclimáticas.

No quarto e último nível, mostram-se dentro de cada agrupamento de terceiro nível, as agregações de unidades de paisagem, cada uma, finalmente, representada individualmente por um símbolo adequado - cores específicas - à sua manifestação em área, com um apropriado epíteto que coloca em destaque as principais características, conjugando peculiaridades do relevo e da vegetação.

Considerando a "Carta delle unità ambientali-paesaggistiche dell'Umbria" (Orsomando, Catorci, Martinelli e Raponi, 2000), a legenda se compõe de quatro níveis:

- o primeiro nível, agrupa blocos de unidades ambientais segundo os tipos de paisagem vegetal: natural, seminatural e antrópica ou cultural;

- o segundo nível, reúne dentro de cada tipo de paisagem vegetal, unidades ambientais agregadas de acordo com os substratos geológicos de referência;

- o terceiro nível, engloba dentro de cada agregado baseado no substrato geológico, unidades ambientais consoantes às características morfológicas do relevo combinadas com aquelas fitoclimáticas;

- o quarto nível, por fim, corresponde às unidades ambiental-paisagísticas singulares, discerníveis pelas cores e respectivas denominações, as quais ressaltam as principais características.

\section{V- As paisagens florestais de Sellano}

O território municipal de Sellano em base à 
"Carta delle unità ambientali-paesaggistiche" se evidencia pela presença de 11 unidades relacionadas e ratificadas a seguir com caracteres em negrito e segundo o esquema hierárquico que considera quatro níveis, descrito anteriormente.

As 11 unidades paisagísticas de Sellano, como se depreende do esquema que segue, adquirem maior valor ambiental e significado histórico-cultural ao se levar em conta que essas estão relacionadas a 4 "sistemas geológicos" (particularmente constituídos por rochas calcárias, formações calco-margosas, margosas, e aluviões atuais e recentes) e a 4 "conjuntos ambientais" (identificáveis, mormente por meio de relevos colinares, montanos, áreas com paleossolos e planícies flúvio-lacustres).
Ainda, das 11 unidades que compõem o conjunto territorial do município, 6 vão individualizar a paisagem vegetal natural, ou seja, a paisagem constituída apenas por elementos de natureza física e biológica, com exclusão das intervenções do homem, como, por exemplo, as florestas espontâneas; uma constitui a paisagem seminatural, derivada das atividades humanas milenares, como as pastagens colinares e baixomontanas; 4 constroem a paisagem humanizada, antrópica ou cultural de formação histórica e desenvolvida pouco a pouco no curso dos séculos através dos múltiplos e incessantes remanejamentos ambientais, como os campos cultivados e abandonados ou os aglomerados urbanos, desde os menores até os maiores.

[Fig.3]

Figura 3-

SELLANO: UNIDADES AMBIENTAL-PAISAGÍSTICAS

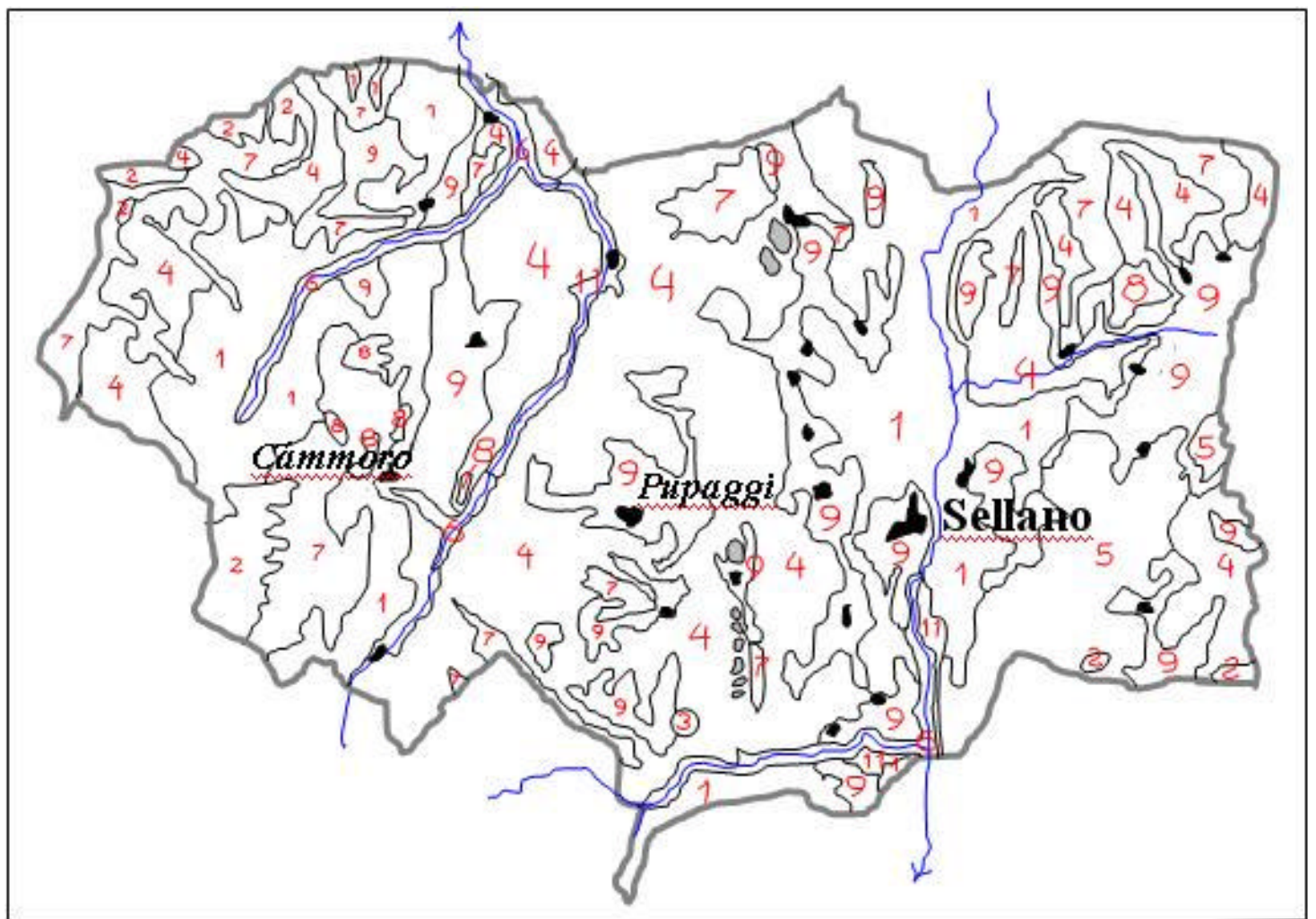



\& ORSOMANDO, E.

\section{Legenda da Figura 3:}

\section{I- Paisagem vegetal natural}

I.I- Sistema dos substratos calcários

I.I.I- Unidades ambientais dos relevos colinares e montanhosos

[1] Vertentes alto-colinares com florestas de Quercus pubescens ${ }^{1}$ ou de Ostrya carpinifolia ${ }^{2}$, às vezes interrompidas por pequenas clareiras de pastagens, de origem secundária, de Bromus erectus ${ }^{3}$

Quercion pubescenti-petraeae ${ }^{1}$, Ostryo-Carpinion orientalis $^{2}$ e Phileo ambigui-Bromion erecti ${ }^{3}$

[2] Vertentes montanas com florestas de Fagus sylvatica ${ }^{1}$ e pequenas pastagens, de origem secundária, de Bromus erectus ${ }^{2}$

Geranio nodosi-Fagion sylvaticae ${ }^{1}$ e Phileo ambiguiBromion erecti2

\section{[3] Áreas rupestres com agrupamentos casmofiticos}

\section{Saxifragion australis}

I.I.II- Unidades ambientais das áreas com paleossolos fersialíticos

[4] Vertentes alto-colinares e submontanas, com fraca declividade e recobertas por paleossolos fersialíticos, com florestas mesófilas de Quercus cerris (Carpinion betuli) e florestas de Castanea sativa $[\bigcirc]$ de origem antrópica

I.II- Sistema dos substratos margosos e Sistema dos substratos calco-margosos

I.II.I- Unidades ambientais dos relevos colinares

[5] Relevos alto-colinares com florestas de Ostrya carpinifolia ou Quercus pubescens' ${ }^{1}$, às vezes interrompidas por pequenas clareiras de pastagem, de origem secundária, de Brachypodium rupestre 2

Ostryo-Carpinion orientalis ${ }^{1}$ (= Carpinion orientalis) e Bromion erecti2

I.III- Sistema dos substratos aluvionares atuais e recentes
I.I.III- Unidades ambientais das planícies flúviolacustres

[6] Leitos fluviais com florestas meso-higrófilas de Salix alba' ou Alnus glutinosa?

Salicion albae ${ }^{1}$ e Alno-Ulmion minoris ${ }^{2}$

\section{II- Paisagem vegetal seminatural}

II.I- Sistema dos substratos calcários e Sistema dos substratos calco-margosos

II.I.I- Unidades ambientais dos relevos colinares e montanhosos

[7] Cimos e vertentes com pastagens de origem secundária de: Bromus erectus ${ }^{1}$, Sesleria nitida ${ }^{1}$ e Cynosurus cristatus ${ }^{2}$

Phileo ambigui-Bromion erecti ${ }^{1}$ e Cynosurion cristati ${ }^{2}$

\section{III- Paisagem antrópica ou cultural}

III.I- Sistema dos substratos calcários, Sistema dos substratos calco-margosos e Sistema dos substratos margosos

III.I.I- Unidades ambientais dos relevos colinares e montanhosos

[8] Implantações arbóreas (reflorestamentos por coníferas)

[9] Áreas agrícolas dos relevos colinares com culturas anuais

[10] Aglomerados urbanos em área rural, de encosta e de colina

III.II- Sistema dos substratos aluvionares atuais e recentes

III.II.I- Unidades ambientais das planícies flúviolacustres

[11] Áreas agrícolas das planícies aluvionares com culturas anuais

Corroborando com as 8 fitocenoses florestais de Sellano já apresentadas e avaliadas nos graus de "valores naturalísticos e estados de conservação", nas correspondentes unidades ambientais arroladas no esquema acima, podem-se fazer as seguintes considerações.

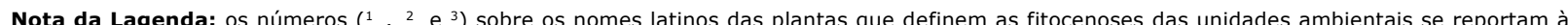
categoria sintaxonômica (colocada logo abaixo em latim) denominada pela Fitossociolgia de "Aliança" (unidade que agrupa várias associações vegetais ecologicamente afins). Leva o sufixo convencional -ion. 
Biodiversidade florestal e paisagística do território

As florestas de Fagus sylvatica, ajuizadas de valor muito elevado, inserem-se na unidade ambiental das vertentes montanas sobre substratos calcários; aquelas de Quercus cerris e de Castanea sativa, ambas julgadas também de valor muito elevado, estão incluídas na unidade ambiental das vertentes alto-colinares e submontanas, de fraca declividade, recobertas com paleossolos fersialíticos; aquelas de Ostrya carpinifolia, de valor médio, enquadram-se na unidade ambiental das vertentes alto-colinares sobre substratos calcários.

As florestas de Quercus pubescens, de valor médio, implantam-se em duas unidades ambientais: aquelas das vertentes alto-colinares sobre substratos calcários e aquelas dos relevos altocolinares sobre substratos margosos e calcomargosos.
As florestas de Quercus cerris e Quecus pubescens, de valor médio, acomodam-se em três diferentes unidades ambientais: a das vertentes alto-colinares sobre substratos calcários; a dos relevos alto-colinares sobre substratos margosos e calco-margosos e a das vertentes alto-colinares e submontanas, com fraca declividade, recobertas com paleossolos fersialíticos.

Por fim, as florestas ciliares de Salix alba, de valor elevado, enquadram-se na unidade ambiental dos leitos fluviais sobre substratos aluvionares atuais e recentes.

Numa fotografia panorâmica de Sellano tomada no sentido de oeste para leste, mostra-se como se dão as articulações entre as unidades ambiental-paisagísticas.

\section{Figura 4
SELLANO: VISÃo PANORÂMICA DAS ARTICULAÇôES ENTRE AS UNIDADES AMBIENTAL- PAISAGÍSTICAS}

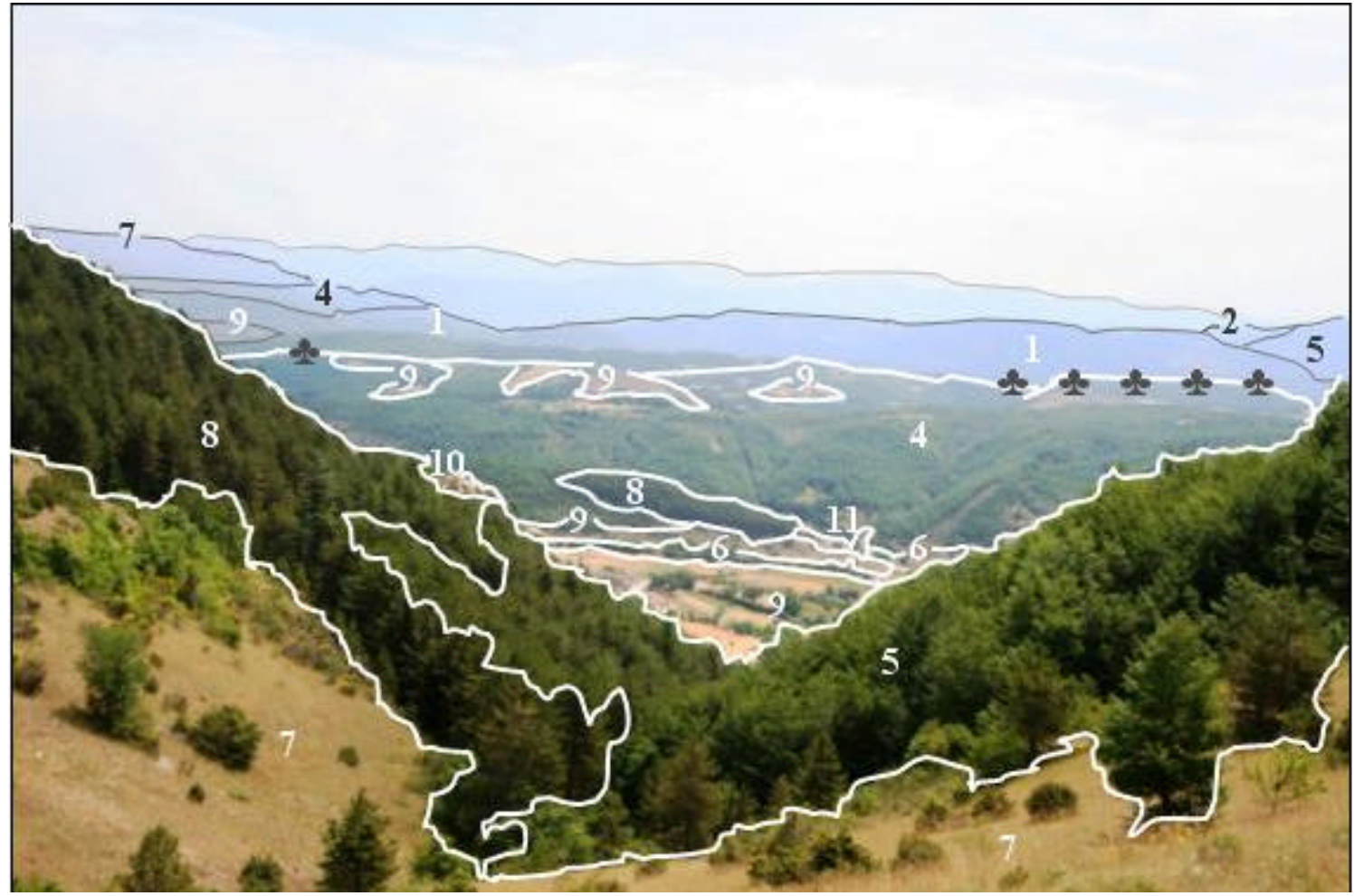



\& ORSOMANDO, E.

\section{Legenda da Figura 4:}

\section{Paisagem vegetal natural}

[1] Vertentes alto-colinares com florestas de Quercus pubescens ou de Ostrya carpinifolia, às vezes interrompidas por pequenas clareiras de pastagens, de origem secundária, de Bromus erectus

[2] Vertentes montanas com florestas de Fagus sylvatica e pequenas pastagens, de origem secundária, de Bromus erectus

[3] (não visível na foto) - Áreas rupestres com agrupamentos casmofiticos

[4] Vertentes alto-colinares e submontanas, com fraca declividade e recobertas por paleossolos fersialíticos, com florestas mesófilas de Quercus cerris (Carpinion betuli) e florestas de Castanea sativa $(*)$ de origem antrópica

[5] Relevos alto-colinares com florestas de Ostrya carpinifolia ou Quercus pubescens, às vezes interrompidas por pequenas clareiras de pastagem, de origem secundária, de Brachypodium rupestre

[6] Leitos fluviais com florestas mesohigrófilas de Salix alba ou Alnus glutinosa

\section{Paisagem vegetal seminatural}

[7] Cimos e vertentes com pastagens de origem secundária de: Bromus erectus, Sesleria nitida e Cynosurus cristatus

\section{Paisagem antrópica ou cultural}

[8] Implantações arbóreas (reflorestamentos por coníferas)

[9] Áreas agrícolas dos relevos colinares com culturas anuais

[10] Aglomerados urbanos em área rural, de encosta e de colina

[11] Áreas agrícolas das planícies aluvionares com culturas anuais

\section{VI- Áreas de importância naturalística de Sellano}

A diversidade florestal, determinada pelas florestas naturais (de Carvalhos, Carpes negros, Carvalhos brancos, Carvalhos brancos com Carvalhos, Faias, e Salgueiros), seminaturais (de Castanheiros) e antrópicas (de Pinho preto), que no conjunto cobrem mais de $60 \%$ da superfície municipal, incluindo núcleos urbanos, capoeiras, sebes, pastagens, pastagens plantadas, culturas agrícolas e outros, gerou um "Complexo ambiental-paisagístico" de elevado valor naturalístico, biogeográfico e histórico-cultural. Esse "Complexo" permitiu o reconhecimento (com áreas distintas) em nível regional e europeu de 4 setores de grande importância naturalística, cujas denominações, relacionadas a seguir, se evidenciam pelos caracteres em negrito.

\section{Áreas de relevante interesse naturalístico da Úmbria:}

"Alta Valle del Vigi e Monti Tito Peneggi" e "Boschi di Terne - Pupaggi".

Deliberazione della Regione dell'Umbria del 22 Luglio 1998, n. 4271. Supplemento ordinario n.1 al "Bollettino Ufficiale" serie generale n. 58 del 23 settembre 1998.

Sítios de Importância Comunitária propostos para a inserção na Rede Ecológica Européia "Natura 2000": Vigi",

"Boschi di Terne e Pupaggi" e "Fiume

Direttiva 92/43/CEE del Consiglio, del 21 Maggio 1992, relativa alla conservazione degli habitat naturali e seminaturali e della flora e della fauna selvatiche. Gazzetta Ufficiale delle Comunità Europee N. L 206/7 del 22.07.92. 


\section{VII- Considerações conclusivas}

Comunicações sobre os aspectos florestais e sobre as tipologias ambientais e paisagísticas de Sellano - "Terra umbra di mezzo", situada entre os Altiplanos de Colfiorito (ao norte) e o Vale Valnerina (ao sul) - foram proferidas na Mesa Redonda Ambiente e Qualidade na cidade. Elas evidenciaram como foi exaltado com grade paixão, não só pelo Prefeito Claudio Guerrini, pelos reputados jornalistas, apresentadores televisivos da RAI, Dr. Federico Fazzuoli e Dr. Franco Valentini, como também pelos presentes nas intervenções e debates finais, o enorme valor biológico que premia o território municipal de Sellano, inserido no contexto regional.

Portanto é oportuno e indispensável salientar a necessidade de aprofundar os estudos, não só no campo geobotânico, como também em outros setores disciplinares naturalísticos (como aqueles zoológicos ou hidrobiológicos) voltados à adequadas formas de gestão e de tutela dos preciosos tesouros abióticos e bióticos do território de Sellano. Tudo isso deverá realizar-se sem nunca descuidar das exigências socioeconômicas que estão na base da vida do próprio território e, especialmente, dos seus habitantes. Com o fim de alcançar tais objetivos,
tornam-se basilares os estudos convergentes sobre adequadas formas de gestão e tutela dos componentes vegetais, particularmente daqueles negligenciados, fortemente reduzidos em extensão e em vias de extinção (como os bosques de Castanheiros).

Para serem eficazes, tais estudos deverão ser alicerçados em mapas geobotânicos em escala grande, realizados com tecnologias informatizadas, com o fim de revelar também os pequenos e numerosos ecossistemas que caracterizam o território municipal e de seguir, ao longo do tempo, as sucessivas variações evolutivo-dinâmicas.

O produto final desse estudo detalhado deverá ser expresso por um documento de síntese, que se proclama através de um mapa das unidades ambientalpaisagísticas com informações capazes de vislumbrar um zoneamento para o território voltado aos objetivos que os administradores políticos, retêm como mais apropriados para garantir a conservação da biodiversidade e a qualidade ambiental.

Concluindo, lembra-se que no debate da citada Mesa Redonda, além das temáticas voltadas à política dirigida a uma melhor gestão do ambiente, foi grande a atenção dada à ativação de módulos promocionais a fim de favorecer a atração turística e dar conhecimento às escolas locais de todos os valores que caracterizam o patrimônio naturalístico e histórico-cultural do Município de Sellano.

\section{Notas}

${ }^{1}$ CEE: Comunidade Econômica Européia, atual União Européia.

${ }^{2}$ CNR: Consiglio Nazionale delle Ricerche, agência nacional de fomento de pesquisas.

${ }^{3}$ A nova associação, denominada Carici sylvaticaeQuercetum cerridis, foi descrita e enquadrada na tabela fitossociológica "N.10 - Boschi di Cerro (Quercus cerris), su calcari silicei o paleosuoli fersiallitici", que consta do trabalho de Catorci e Orsomando (2001); atualmente constitui uma ftocenose florestal endêmica para o território de Sellano e dos Planaltos de Colfiorito. 

\& ORSOMANDO, E.

\section{Bibliografia}

ALVES, T. "Paisagens: em busca do lugar perdido". Finisterra, 36(72):67-74, 2001.

BEROUTCHACHVILLI, N. e BERTRAND, G. "Le géossystème ou système territoriel naturel". Revue Géographique des Pyrénées, et du SudOuest, 49, (2): 167-180, 1978.

BERTALANFFY, L. v. General system theory: foundations, development, application. New York: George Braziller, 1968.

BERTIN, J. La graphique et le traitement graphique de l'information. Paris: Flammarion, 1977.

BERTIN, J. Sémiologie graphique: les diagrammes, les réseaux, les cartes. Paris: Mouton Gauthier-Villars, 1973.

BERTRAND, G. "Paysage et géographie physique globale: équisse méthodologique". Revue Géographique des Pyrénées et du Sud-Ouest, 39(3): 249-272, 1968.

BLASI, C. et al. "Classificazione e cartografia del paesaggio: i sistemi e i sottosistemi di paesaggio del Molise". Informatore Botanico Italiano, (32): 15-20, 2000.

BLASI, C., SMIRAGLIA, D. e CARRANZA, M. "Analisi multitemporale del paesaggio e classificazione gerarchica del territorio: il caso dei Monti Lepini (Italia Centrale)". Informatore Botanico Italiano, 35(1): 31-40, 2003.

CARRÉ, J. "Cartographie et environnement". Bull. Comité Français de Cartographie, (76): 40-56, 1978.

CASTRO, I.E. "O problema da escala". In: CASTRO, I.E. Geografia: conceitos e temas. Rio de Janeiro: Bertrand Brasil, 1995.

CATORCI A. e ORSOMANDO E. "Note illustrative della Carta della vegetazione del Foglio Nocera Umbra (N. 312 - Carta d'Italia I.G.M. - 1: 50.000)". Braun-Blanquetia, 23: 7-108, 2001.

CRUZ, O. "A escala temporal-espacial nos estudos dos processos geomorfológicos erosivos atuais". Geomorfologia, (33): 1 - 12, 1985.

CULLOT, M. "Points de vue sur la perception des paysages". L'Espace Géographique, 15(3): 211217, 1986.

DRAGUT, L. Geografia peisajului. Cluj-Napoca: Presa Universitara Clujeana, 2000.

FALINSKI, J.B. e PEDROTTI, F. "The vegetation and dynamical tendencies in the vegetation of Bosco Quarto, Promontorio del Gargano, Italy". Braun-Blanquetia, (5): 1-31, 1990.

FENAROLI L., GAMBI G. "Alberi. Dendroflora italica". Museo Tridentino di Scienze Naturali. Trento, 1976.

FERREIRA, M. C. "Mapeamento de unidades de paisagem com Sistemas de Informação Geográfica: alguns pressupostos fundamentais". Geografia, 22 (1): 23-36, 1997.

FORMAN, R.T.T. e GODRON, M. Ladscape ecology, New York: J. Wiley \& Sons, 1986.

FRÉMONT, A. "Les profondeurs des paysages géographiques". In: ROGER, A. (org.). La théorie du paysage en France. 1995.

FRÉMONT, A. "L'écologie et le paysage". Notes Recherches, Soc. Géogr. Liège, (8): 37-48, 1987.

GÉHU, J.M. "L'analyse symphytosociologique et géographique de l'espace: théorie et méthodologie". Collection Phytosociologique, (17) : 11-46, 1991.

GODART, M.F. e DECONINK, M. "Les paysages à travers différents regards". Contributii Botanice, 38(2): 5-11, 2003.

INGEGNOLI, V. Fondamenti di ecologia del paesaggio. Torino: Cittàstudi Edizioni, 1993.

INGEGNOLI, V. Landscape ecology: a widening foundation. Tokyo: Springer, 2002.

ISACHENKO, T.I. Principles and methods of vegetation mapping. Moscou : U.P.M., 1962.

JOURNAUX, A. "Présentations des cartes de 
Biodiversidade florestal e paisagística do território

municipal de Sellano - Úmbria - Itália, pp. 185 - 211

I'environnement de Basse Normandie: réalisations actuelles; premiers resultats de la télèdetection". In : Symposium Iternational sur la Cartographie de I'Environnement et de sa Dynamique. Caen, 1980.

JOURNAUX, A. Légende pour une carte de I'environnement et de sa dynamique. Caen : Centre de Géomorphologie du CNRS, 1975.

KONDRACKI, J. e OSTROWSKI, J. "Map of the synantropization of the environment in Poland". In: IGU/ICA. Examples of environmental maps. Madrid: IGN, 1980.

LACOSTE, Y. "A quoi sert le paysage? Qu'est-ce qu'un beau paysage?" Herodote, (7): 3-41, 1977.

LECOEUR, C. "Le paysage comme cadre physique". Herodote, (41): 45-50, 1987.

LEHANN, E. e BENEDICT, E. "The environmental situation of the Halle-Leipzig region; detail from a map 1: 500.000". In: IGU/ICA. Examples of environmental maps. Madrid: IGN, 1980.

MAC. EACHREN, A.M. e TAYLOR, D.F. (ed.) Visualization in modern cartography. Londres: Elseiver Science Ltd., 1994.

MARFIL, A. et al. "Unidades de paisaje en el Parque Natural de Cabo de Gata-Nijar (Almeria, España)". Colloques Phytosociologiques, (21): 127-147, 1993.

MARTINELLI, M. "Cartografia ambiental: que cartografia é essa?" In: Souza M.A.A. (org). O novo mapa do mundo. Natureza e sociedade de hoje: uma leitura geográfica. São Paulo: Hucitec-Anpur, 1993.

MARTINELLI, M. "Cartografia ambiental: uma cartografia diferente?". Revista do Departamento de Geografia, (7): 61-80, 1994.

MARTINELLI, M. "Cartografia do turismo e imaginário". In: RODRIGUES, A.B. (org.). Turismo rural: práticas e perspectivas. São Paulo: Contexto, 2001.

MARTINELLI, M. "Discussione metodologica su un approccio della rappresentazione cartografica dell'impatto ambientale. Esempio: Camerino ed i suoi dintorni". Boll. Soc. Ital. Ecologia, 8 (5): 226. 1987.

MARTINELLI, M. "La cartografia delle unità ambientali come sintesi del paesaggio". Colloques Phytosociologique: la vegetazione postglaciale, (35): 124-125, 1998.

MARTINELLI, M. "La cartographie environnementale: une cartographie de synthèse". Phytocoenosis, (11): 123-130, 1999.

MARTINELLI, M. "Orientação semiológica para as representações da geografia: mapas e diagramas". Orientação, (8): 53-62, 1990.

MARTINELLI, M. As representações gráficas da geografia: os mapas temáticos. São Paulo: USP, 1999.

MARTINELLI, M. Gráficos e mapas: construa-os você mesmo. São Paulo: Moderna, 1998.

MARTINELLI, M. Os mapas da geografia e cartografia temática. São Paulo: Contexto, 2003.

MARX, K. e ENGELS, F. The German ideology. New York: International Publishers, 1979.

MAYSTRE, Y. "Le concept d'environnement et sa dynamique cartographique". In: Symposium Internationale sur la Cartographie de l'environnement et sa dynamique, (1): 109-119, 1979.

NAVEH, H. "Landscape ecology as an emerging branch of human ecosystem science". Adv. Ecol. Res. (12): 189-237, 1982.

NAVEH, Z. e LIEBERMAN, A.S. Landscape ecology, theory and application. New York: Springer Verlag, 1984.

ORSOMANDO E. "Carta della vegetazione del Foglio Foligno (N. 324 - Carta d'Italia I.G.M.I. 1: 50.000)". Braun-Blanquetia, 10: 27-43, 1993.

ORSOMANDO E., BALLELLI S., CATORCI A., FORMICA E. "Atlante iconografico di piante rare o significative della Selva di Castelfidardo. Area Floristica delle Marche". Dipartimento di Botanica ed Ecologia - Università di Camerino. Italia 

\& ORSOMANDO, E.

Nostra - Sezione di Castelfidardo. Comune di Castelfidardo. Recanati: Tecnostampa, 1992.

ORSOMANDO E., CATORCI A. "Carta del Paesaggio Vegetale. Consorzio della Bonificazione Umbra. Bacino idrografico dei Fiumi Topino e Marroggia (Scala 1: 100.000)". Consorzio della Bonificazione Umbra. Dipartimento di Botanica ed Ecologia Università di Camerino. Regione dell'Umbria. Area Assetto del Territorio e P.U.T.. Comprensorio "Topino e Marroggia". Firenze: SELCA, 1998.

ORSOMANDO E., CATORCI A. "Carta della vegetazione naturale potenziale dell'Umbria (Scala 1:200.000). Note Esplicative". Regione dell'Umbria - Direzione Regionale Politiche Territoriali Ambiente ed Infrastrutture. Univ. di Camerino, Dipartimento di Botanica ed Ecologia. Firenze: SELCA, 1999.

ORSOMANDO E., CATORCI A. "Carta Geobotanica con principali classi di utilizzazione del suolo. Scala 1: 50.000. Fogli I.G.M.: 278 , 279, 289, 290, 291, 299, 300, 301, 309, 310, 311, 312, $321,322,323,324,325,333,334,335,336$, 337, 345, 346, 347 e 356". Regione dell'Umbria - Area Assetto del Territorio e P.U.T. Dipartimento di Botanica ed Ecologia, Università di Camerino. Firenze: SELCA, 1999.

ORSOMANDO E., CATORCI A., MARTINELLI M. e RAPONI M. "Carta delle unità ambientalipaesaggistiche dell'Umbria. Scala 1: 100.000". Regione dell'Umbria, Direzione Regionale Politiche Territoriali Ambiente ed Infrastrutture. Univ. di Camerino, Dipartimento di Botanica ed Ecologia. Universidade de São Paulo, Departamento de Geografia. Firenze: SELCA, 2000.

ORSOMANDO E., CATORCI A., PITZALIS M., RAPONI M. "Carta fitoclimatica dell'Umbria. Scala 1: 200.000. Note esplicative". Regione dell'Umbria. Università di Camerino. Università di Perugia. Firenze : SELCA, 1999.

OZENDA, P. "De la carte de la végétation à une carte de l'environnement". Doc. Cart. Ecol., XIII: 1-8, 1974.
OZENDA, P. Biogéographie végétale. Paris: Armand Colin, 1964.

OZENDA, P. La cartographie écologique et ses applications. Paris: Masson, 1986.

PALSKY, G. Des chiffres et des cartes: Ia cartographie quantitative au XIXe siècle. Paris: Comité des Travaux Historiques et Scientifiques, 1996.

PEDROTTI, F. "Le serie di vegetazione nella cartografia ambientale". Genio rurale. 61(1): 1517, 1998.

PEDROTTI, F. "Vegetazione e stabilità". Terra (1): 8-14, 1987.

PEDROTTI, F. Carta delle unità ambientali dei Monti Sibillini. Firenze: SELCA, 1999.

PEDROTTI, F. Cartografia geobotanica. Bologna: Pitagora Editrice, 2004.

PEDROTTI, F. e MARTINELLI, M., "A cartografia das unidades de paisagem: questões metodológicas". Revista do Departamento de Geografia, (14): 39-46, 2001.

PEDROTTI, F. et al. "Le unità ambientali de Parco Nazionale dello Stelvio". L'uomo e I'ambiente, (28): 1-104, 1997.

PIGNATTI, S. Ecologia del paesaggio. Torino: UTET, 1997.

PINTO-CORREIA, T. et al. "Identificação de unidades de paisagem: metodologia aplicada a Portugal Continental". Finisterra, 36(72): 195206, 2001.

REGIONE DELL'UMBRIA. GIUNTA REGIONALE. ASSESSORATO ASSETTO DEL TERRITORIO E PUT, Annuario delle statistiche territoriali. Perugia: SITER, 2000.

RIVAS MARTINEZ, S. Biogeografía y vegetación. Madrid: Real Acad. Ciencias Exactas, Físicas y Naturales, 1985.

RODRIGUEZ, J.M.M. e SILVA, E.V. da. "A classificação das paisagens a partir de uma visão geossistêmica". Mercator. Revista de Geografia da UGC, 1(1): 95-112, 2002. 
Biodiversidade florestal e paisagística do território

municipal de Sellano - Úmbria - Itália, pp. 185 - 211

SANTOS, M. Técnica, espaço, tempo. Globalização e meio técnico-científicoinformacional. São Paulo: Hucitec. 1994.

SOTCHAVA, V.B. "The study of geosystems". Special issue for the XXIII International Geographic Congress. (51): 3-40, 1976.

TANSLEY, A.G. "The use and abuse of vegetational concepts and terms". Ecology, (16): 284-307, 1935.

TRICART, J. e KILIAN, J. L'éco-géographie et I'aménagement du milieu naturel. Paris: Maspero, 1979.

TRICART, J. Ecodinâmica. Rio de Janeiro: IBGE/ SUPREN, 1977.

TROLL, C. "Landscape ecology". Paper S. 4, Publ. ITC-Unesco, 1966.

TROLL, C. "Luftbildenplan und ökologische bodenforschung". In: ZEITSCHRIFT, D. e GESELLSCHAFT, F. Erdkunde, Berlin, 1939.

TROPPMAIR, H. "A cobertura vegetal primitiva do estado de São Paulo". Biogeografia, (1), 1969.

TUXEN, R. "Die heutige potentielle natürliche Vegetation als Gegenstand der Vegetationskartierung", Angew. Pflanzensoziologie, (13):1-55, 1956.

VOS, W. e STORTELDER, A. Vanishing Tuscan landscapes: landscape ecology of a submediterranean-montane area. Wageningen: Pudor Scientific Publ., 1992.

ZONNEVELD, I.S. "The land unit: a fundamental concept in landscape ecology and its applications". Landscape ecology, 3(2): 67-86. 1989.

Trabalho enviado em abril de 2007

Trabalho aceito em maio de 2007 
